\title{
Upper Extremity Pain in Spinal Cord Injury (Sci) Patients
}

\author{
Awni Al Hadid*, Baraa Al Shagoor, Hussein Dmour, Khaled Bani Hani, Abeer Al Omari \\ Royal Medical Services, Jordan \\ *Corresponding author: Awni Al Hadid, Royal Medical Services, Jordan
}

\begin{abstract}
ARTICLE INFO
Received: 幽 April 16, 2019

Published: April 24, 2019

Citation: Awni Al H, Baraa Al S, Hussein D, Khaled B Ha, Abeer Al O. Upper Extremity Pain in Spinal Cord Injury (Sci) Patients. Biomed J Sci \& Tech Res 17(3)-2019. BJSTR. MS.ID.003002.
\end{abstract}

Keywords: SCI; Upper Extremity Pains; Shoulder; Wrist; Location
ABSTRACT

Introduction: Upper extremity pain is a common problem in SCI patients in the acute and chronic stages after their injury, and that could be severe enough to interfere with Activity of Daily Livings (ADLs).Heavy load in upper extremity during wheelchair propulsion and other weight bearing activities such as transfer and weight shifting is the main cause behind upper extremity pain and problems.

Objectives: To investigate the incidence of upper extremity complaints among SCI patients, and to study the predicting factors and main etiologies resulting in these complaints among patients who are followed in SCI clinic at the Royal Rehabilitation Centre, Royal Medical Services.

\section{Methods and subjects:}

Study design and setting: A retrospective design will be conducted to collect data fromthe electronic notes of SCI patients followed in SCI clinic at the Royal Rehabilitation Centre, Royal Medical Services in a one-year period of time since Jan2018 till Jan 2019.

Study sample: A total of 200 files of SCI patients will be included.

Study results: The prevalence of upper extremity pains among patients with SCI was about $84 \%$. The mean age of study participants was $43.78 \pm 13.5$ years. Sixty percent of study participants were males. Shoulders and wrists were the most frequent locations affecting by upper extremity pains.

Conclusions: Patients with SCI have high rates of upper extremity pains particularly in shoulder or wrist.

\section{Introduction}

Spinal cord injury (SCI) can be described as an injury involving the spinal cord that can be caused by compulsion, incision or contusion. The injury leads to alterations or interruptions of spinal cord functions [1]. SCI usually is a reason for various types of disabilities in children [2]. It has been estimated that approximately 40 million people at global level are affected by SCI. The majority of these injured patients are young men. The majority of cases among children are associated with sports, particularly football [3-5]. Estimates on international level pointed out that the most frequent causes of SCI are due to traffic accidents, gunshot injuries, knife injuries, falls and sports injuries [1]. Patients with SCI usually suffer from upper extremity (UE)pain with rates varied from $26 \%$ to $96 \%$
[6-7].About $35 \%$ of patients with SCI patients had severe pain [810].The pain associated with SCI has various influences including quality of life, mood, and function [11-12]. It has been indicated that with increased medical care with the persons who have SCI, the life expectancy for those patients has increased. A variety of problems are associated with SCI such as pain in the upper extremity [13].

\section{Study objectives}

To investigate the incidence of upper extremity complaints among SCI patients, and to study the predicting factors and main etiologies resulting in these complaints among patients who are followed in SCI clinic at the Royal Rehabilitation Centre, Royal Medical Services. 


\section{Methods and Subjects}

\section{Study design and setting}

A retrospective design was conducted to collect data from the electronic notes of SCI patients followed in SCI clinic at the Royal Rehabilitation Centre, Royal Medical Services in a one year period of time since Jan2018 till Jan 2019.

\section{Study sample}

A total of 200 files of SCI patients were included.

\section{Inclusion criteria}

SCI patients, tetraplegic and paraplegic, classified as A, B, C, or $\mathrm{D}$ according to the American Spinal Cord Injury Association(ASIA), Impairment Scale between 18 to 65 years of old.

\section{Exclusion criteria}

History of upper extremity trauma, progressive disease, Rheumatological disease that may manifest as musculoskeletal problem such as Rheumatoid arthritis, Ankylosing Spondylitis and haemodialysis patient with AV fistula.

\section{Statistical analysis}

All data were entered into SPSS version 21 for statistical analysis. Data were presented as percentage, frequencies, means and standard deviations to describe study variables.

\section{Results}

\section{Frequency of Age and Gender by Study Participants}

As it can be seen in (Table 1, Figures 1 and 2), the mean age of study participants was $43.78 \pm 13.5$ years, $60 \%$ of participants were males, and the prevalence of UE pain in patients with SCI was $84 \%$.

Table 1: Frequency of age and gender by study participants.

\begin{tabular}{|c|c|}
\hline Variable & Description \\
\hline Age $(\mathrm{M} \pm \mathrm{SD}$ ) years & $43.78 \pm 13.5$ \\
\hline Gender $(\mathrm{N}, \%):$ & $120(60 \%)$ \\
- Males & $80(40 \%)$ \\
- Females & $169(84 \%)$ \\
\hline Upper extremity pain $(\mathrm{N}, \%):$ & $31(16 \%)$ \\
\hline
\end{tabular}

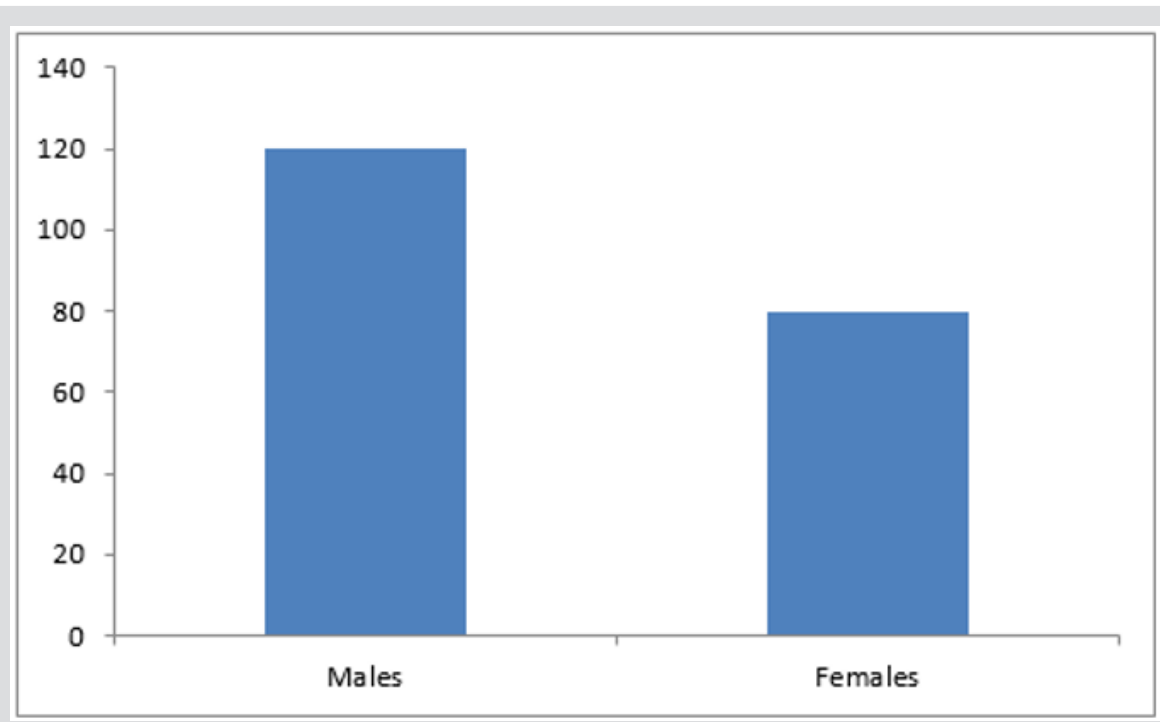

Figure 1: The frequency of gender by study participants.

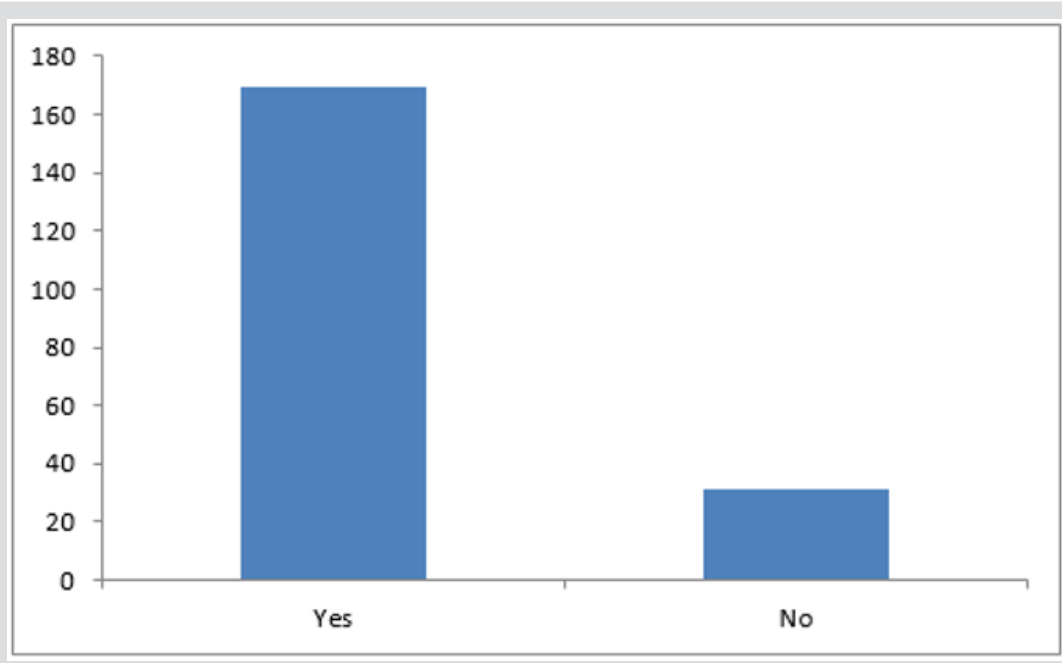

Figure 2: Frequency of upper extremity pain by study participants. 
Location and degree of severity of upper extremity pain among patients with SCI

As demonstrated in (Table 2 and Figure 3), the most frequent upper extremity pain was in shoulders, followed by wrist, elbow, and hand. Mild severity was noted in left wrist, while intermediate or moderate severity was mostly exhibited in the right elbow, and the most severity was observed in the right shoulder.

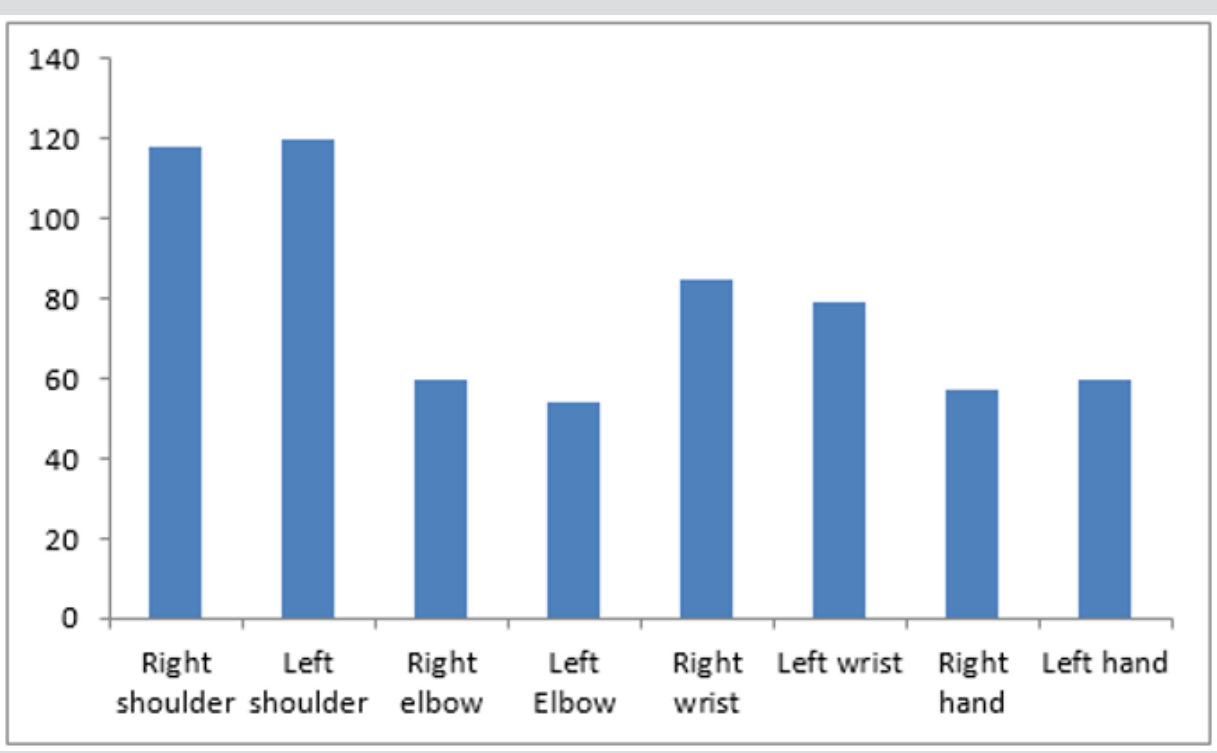

Figure 3: Location and severity of upper extremity pain in patients with SCI.

Table 2: Location and degree of severity of upper extremity pain among patients with SCI.

\begin{tabular}{|c|c|c|c|c|}
\hline Location & Patient No & Mild \% & Intermediate $\%$ & Severe $\%$ \\
\hline Right shoulder & 118 & $37.5 \%$ & $46.3 \%$ & $16.2 \%$ \\
\hline Left shoulder & 120 & $44.3 \%$ & 47.5 & $8.2 \%$ \\
\hline Right elbow & 60 & $43.5 \%$ & $51.3 \%$ & $5.2 \%$ \\
\hline Left elbow & 54 & $46.5 \%$ & $43.6 \%$ & $9.9 \%$ \\
\hline Right wrist & 85 & $43.9 \%$ & $41.8 \%$ & $14.3 \%$ \\
\hline Left wrist & 79 & $60.9 \%$ & $32 \%$ & $7.1 \%$ \\
\hline Right hand & 57 & $51.5 \%$ & $35.5 \%$ & $13 \%$ \\
\hline Left hand & 60 & $49.8 \%$ & $33.2 \%$ & $17 \%$ \\
\hline
\end{tabular}

\section{Discussion}

The present study was conducted to explore the prevalence of upper extremity pain among patients SCI. Across the literature, great interest was withdrawn to problems related to musculoskeletal system among patients with chronic SCI [13-17]. The data of the present study indicated that about $84 \%$ of patients with SCI suffered from upper extremity pain. Previous studies reported varied rates of upper extremities among SCI patients. In their study, Dalyan et al [13] reported a prevalence of 58\%, while Kentar et al [18] reported $81 \%$ prevalence of upper extremity pain among patients with SCI. The data of the present study showed that the most existence of upper extremity pain among patients with SCI was in shoulder and wrist. These findings are consistent with other studies in literature [13,19-22].

\section{Conclusion}

The present study showed that the prevalence of upper extremity pain among patients with SCI patients was about $84 \%$, and the most pains were in shoulders or wrists.

\section{References}

1. Kemal Nas, Levent Yazmalar, Volkan Şah, Abdul kadir Aydın, Kadriye Öneş (2015) Rehabilitation of spinal cord injuries. World J Orthop 6(1): 8-16.

2. Yıldırım K, Şengel K (2004) Spinal kordyaralanmalarıverehabilitasyonu (Spinal cord injury and rehabilitation). KlnkAkt Tıp Derg 4: 26-38.

3. Mahan ST, Mooney DP, Karlin LI, Hresko MT (2009) Multiple level injuries in pediatric spinal trauma. J Trauma 67: 537-542.

4. Yip PK, Malaspina A (2012) Spinal cord trauma and the molecular point of no return. Mol Neurodegener 7: 6 .

5. Cantu RC, Li YM, Abdulhamid M, Chin LS (2013) Return to play after cervical spine injury in sports. Curr Sports Med Rep 12: 14-17.

6. M Dijkers, T Bryce, J Zanca (2009) Prevalence of chronic pain after traumatic spinal cord injury: a systematic review. J Rehabil Res Dev 46: 13-29.

7. B Chi, B Chau, E Yeo, P Ta (2019) Virtual reality for spinal cord injuryassociated neuropathic pain: Systematic review. Annals of Physical and Rehabilitation Medicine 62: 49-57.

8. PJ Siddall, DA Taylor, JM McClelland, SB Rutkowski, MJ (1999) Cousins Pain report and the relationship of pain to physical factors in the first 6 months following spinal cord injury Pain. 81: 187-197. 
9. P Siddall, J Loeser (2001) Pain following spinal cord injury Spinal Cord 39: 63-73.

10. PJ Siddall, JM McClelland, SB Rutkowski, MJ (2003) Cousins. A longitudinal study of the prevalence and characteristics of pain in the first 5 years following spinal cord injury Pain 103: 249-257.

11. JM Hoffman, CH Bombardier, DE Graves, CZ Kalpakjian, JS Krause A (2011) Longitudinal Study of Depression From 1 to 5 Years After Spinal Cord Injury. Arch Phys Med Rehabil 92: 411-418.

12. CMC van Leeuwen, MWM Post, FWA van Asbeck, HMH Bongers Janssen, LHV van der Woude, et al (2012) Life satisfaction in people with spinal cord injury during the first five years after discharge from inpatient rehabilitation. DisabilRehabil 34: 76-83.

13. M Dalyan, DD Cardenas, B Gerard (1999) Upper extremity pain after spinal cord injury. Spinal Cord 37: 191-195.

14. Karlsson AK (1999) Autonomic dysreflexia. Spinal Cord 37:383-391.

15. Anderson KD (2004) Targeting recovery: priorities of the spinal cord injured population. J Neurotrauma 21: 1371-1383.

16. Kitzman P (2006) Changes in vesicular glutamate transporter 2, vesicular GABA transporter and vesicular acetylcholine transporter

\section{ISSN: 2574-1241}

DOI: 10.26717/BJSTR.2019.17.003002

Awni Al Hadid. Biomed J Sci \& Tech Res

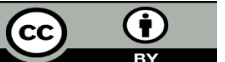

This work is licensed under Creative Commons Attribution 4.0 License

Submission Link: https://biomedres.us/submit-manuscript.php labeling of sacrocaudalmotoneurons in the spastic rat. Exp Neurol 197: 407-419.

17. Alexander G Rabchevsky, Patrick H Kitzman (2011) Latest Approaches for the Treatment of Spasticity and AutonomicDysreflexia in Chronic Spinal Cord Injury. The Journal of the American Society for Experimental NeuroTherapeutics 8: 274-282.

18. Kentar Y, Zastrow R, Bradley H, Brunner M, Pepke W, et al. (2018) Prevalence of upper extremity pain in a population of people with paraplegia. Spinal Cord 56(7): 695-703.

19. Nichols PJR, Norman PA, Ennis JR (1979) Wheelchair user's shoulder? Shoulder pain in patients with spinal cord lesions. Scand J Rehab Med 11: 29-32.

20. Alijure J (1985) Carpal tunnel syndrome in paraplegic patients. Paraplegia 23: 182-186.

21. Sie IH, Waters RL, Adkins RH, Gelmann H (1992) Upper extremitypain in the postrehabilitation spinal cord injured patient. ArchPhys Med Rehabil 73: 44-48.

22. Campbell CC, Koris MJ (1996) Etiologies of shoulder pain in cervical spinal cord injury. Clin Orthop 322: 140-145.

$\begin{array}{ll}\text { BIOMEDICAL } & \text { Assets of Publishing with us } \\ \text { RESEARCHES } & \text { - Global archiving of articles } \\ & \text { - Immediate, unrestricted online access } \\ & \text { - Rigorous Peer Review Process } \\ \end{array}$

